\title{
A contrarreforma do Ensino Médio - Lei 13.415/2017: educação de resultados?
}

\author{
The counter reform of High School - Law 13.415/2017: is it an education of results? \\ Contrarreforma de la Enseñanza Secundaria - Ley 13415/2017: ¿Una educación de resultados?
}

Maria Abádia Silva - Universidade de Brasília - UnB | Faculdade de Educação - Departamento Teoria e Fundamentos | Brasília | DF | Brasil. E-mail: abadiaunb@gmail.com

Resumo: O presente artigo parte da compreensão de que a política educacional integra e é parte da política econômica e da complexidade histórica do direito à educação. Elege como objetivo problematizar as razões do Governo Federal e empresários do setor educacional que ensejaram a Lei $n^{\circ} 13.415 / 2017$, que instituiu a Política de Fomento à implementação de Escolas de Ensino médio em tempo integral. Discute algumas implicações na formação dos estudantes trabalhadores e no trabalho docente, apontando como, historicamente, o Banco Mundial e OCDE forjam políticas para a educação básica com a anuência dos governos, partidos políticos e empresários do setor educacional e midiático, num movimento de restrição e comprometimento do direito à Educação.

Palavras-chave: Educação básica. Banco Mundial e OCDE. Ensino médio e política educacional.

Abstract: This issue starts from the comprehension that educational policy is part of the economic policy and of the historical complexity of the right to the Education, and problematizes the reasons of the federal government and educational sector entrepreneurs who predispose the creation of the law number 13.415/2017, which establishes the implementation of the full time schools of High School. It discusses some implications on the High School for worker students' life and in teachers training. It points how historically the World Bank and the OECD forge policies for basic education with government, policy parties and education sector entrepreneurs and media agreement, in a restrictive and compromise movement to the right to the Education.

Keywords: Basic education. World Bank and OECD. High school and educational policy.

Resumen: Este artículo parte de la compresión de que la política educacional integra y es parte de la política económica y d la complexidad histórica del derecho a la Educación. Elige como objetivo problematizar las razones del Gobierno Federal y empresarios del sector educacional que facilitar la Ley 13.415/2017, que instituyó la Política de Promoción para la implementación de Escuelas de Enseñanza Secundaria en tiempo integral. Discute algunas implicaciones en la formación de los estudiantes trabajadores y en el trabajo docente, apuntando cómo, históricamente, el Banco Mundial y la OCDE forjan políticas para Educación Básica con el consentimiento de los gobiernos, partidos políticos y empresarios del sector educacional y mediático, en un movimiento de restricción y comprometimiento del derecho a la Educación.

Palabras clave: Educación Básica. Banco Mundial y OCDE. Enseñanza Secundaria y Política Educacional.

- Recebido em 10 de abril de 2018 • Aprovado em 02 de maio de 2019 • e-ISSN: 2177-5796

DOI: http://dx.doi.org/10.22483/2177-5796.2019v21n2p379-396

Copyright @ 2019. Conteúdo de acesso aberto, distribuído sob os termos da Licença Internaonal da CreativeCommons - CC BY-NC-SA Atribuição Não Comercial (https://br.creativecommons.org/licencas/) - Permite distribuição e reprodução, desde que atribuam os devido créditos à publicação, ao autor(es) e que licenciem as novas criações sob termos idênticos. 


\section{Introdução}

A Constituição Federal de 1988 (BRASIL, 1988) consagrou a educação básica obrigatória, um direito subjetivo conquistado pela sociedade brasileira ao longo de muitas lutas, marchas, greves, audiências, atos públicos e manifestações. E a Emenda Constitucional 59/2009 (BRASIL, 2009) tornou o Ensino Médio obrigatório para a faixa etária de 14 a 17 anos, este objeto de disputa dos empresários do setor educacional, governos, parlamentares, executivos, partidos políticos, setores religioso e de telecomunicações. Nesta luta cheias de tensões, os movimentos sociais, associações científicas e confederação dos trabalhadores conseguiram instituir, na legislação, o Ensino Médio, última etapa da educação básica, como um direito. Anos depois, em 2017, os grupos e os setores conservadores rejeitaram, novamente, uma proposta que defendia as finalidades e concepção de formação fundamentada no desenvolvimento humano, cognitivo, moral, intelectual como princípio educativo e formativo, que torna os seres humanos, humanos e sociais, e aprovaram a Lei ${ }^{\circ}$ 13.415/2017, que institui a Política de Fomento à implementação de Escolas de Ensino médio em tempo Integral.

O Governo Federal aponta como justificativas que: o Ensino Médio está desgastado, com altos índices de evasão e distorção idade/série; a necessidade de readequação curricular no Ensino Médio, de forma a torná-lo atraente para os jovens e possibilitar sua inserção profissional no mercado; e os conteúdos formativos não estão em sintonia com o mercado de trabalho. De acordo com dados do IDEB - Índice de Desenvolvimento da Educação Básica de 2015 divulgados pelo Ministério da Educação (BRASIL, 2015), o Ensino Médio é o que está em pior situação, quando comparado às séries iniciais e finais da educação fundamental. São estes os elementos postos na exposição de motivos da proposta que ensejou a Medida Provisória n ${ }^{\circ}$ 746/2016 (BRASIL, 2016).

De outro lado, os empresários e comerciantes dos setores de serviços em geral, como shoppings, hotéis, hospitais, clínicas, comércio, supermercados, escritórios, fábricas, indústrias, ferrovias, oficinas, usinas, padarias, lojas, armazéns, frutarias, restaurantes, serviços de saúde, de alimentação, estética, transporte, turismo, cultura, museus, lazer, livrarias, serviços agrícolas e da construção civil também interpelam sobre a concepção e as finalidades da formação escolar destinada aos adolescentes e jovens trabalhadores. 
Adicionam-se na disputa, ainda, os segmentos sociais e populares, associações científicas e confederação de trabalhadores da educação propondo fins, finalidades, identidades, financiamento público adequado e objetivos para a educação básica há décadas. As discussões abrangem: concepções, formar para quê? Como? Para o trabalho? Para que tipo de trabalho diante de tanto desemprego? Ou formar para prosseguir nos estudos superiores? Uma formação humanística ou profissional? São dilemas vividos em todos os tempos, velhas e novas questões, além das dificuldades dos estudantes de conciliar estudo no período noturno, trabalho, desemprego e compromissos familiares.

Neste movimento, em termos metodológicos, os documentos são tomados como parte do real, mas não expressam todo o real. São parcelas que fazem parte do todo. Busco apreender a legislação e os documentos como fontes de estudo da política educacional e, assim, captar a dinamicidade, contradições, inter-relações, intenções e a práxis social construída e reconstruída na complexidade do real, nas condições de vida material em sociedade.

Parte-se ainda da complexidade histórica do direito à Educação pública no país. Assumese aqui, que a política educacional é parte da política econômica (VIEIRA, 1992) e num esforço teórico-didático busco evidenciar as intenções encobertas e as razões oficiais que sustentaram a contrarreforma do Ensino Médio - Lei no 13.415, de 16 de fevereiro de 2017, para em seguida, construir reflexões sobre algumas implicações no Ensino Médio Regular para os estudantestrabalhadores e para o trabalho docente. Passemos à reflexão!

\section{Contexto histórico e razões para a contrarreforma do Ensino Médio: Lei no 13.415/2017}

No Brasil, desde o início, os grupos oligárquicos ocuparam o Estado brasileiro, fazendo dele um instrumento para prebendas, favorecimentos e privilégios, ou um ente para garantir bons negócios e contratos vantajosos para os mandatários políticos, religiosos e comerciantes portugueses. Os latifundiários, os senhores de engenho, escravocratas e grupos de famílias abastadas criaram a nação prescindindo da escolarização de toda população. Se em outros países latinos e europeus já havia uma visão de que uma das tarefas dos governantes era educar a população; aqui, para os dirigentes, isto não tinha sentido. Ocuparam a terra e, logo depois, passaram a reparti-la com os fidalgos, senhores de engenho, fazendeiros e comerciantes. Famílias de posse foram agraciadas com terras, títulos nobiliárquicos, ordenamento jurídico e as bênçãos da igreja católica. 
Entretanto, foi na República que o modo de produção capitalista passou a exigir trabalhadores qualificados para a indústria, mineração, transporte, construção civil, obras portuárias, engenharias, infraestrutura, ferrovias, viadutos, rodovias, pontes, aeroportos, eletricidade e setor petroquímico. Adiciona-se profissionais especializados para serviços alfandegários, tributários, finanças e bancos. Neste movimento, o Estado brasileiro, ocupado pelas oligarquias, conduziu o projeto nacional desenvolvimentista movido pelas disputas intra e inter elites, ávidas por expansão de negócios. Nas tensões políticas e jurídicas inter forças econômicas, a educação pública tornou-se uma questão nacional, não pelo reconhecimento do Estado, de sua necessidade para a formação humana, mas por carência de técnicos e trabalhadores aptos para o trabalho nas indústrias, fábricas, usinas, construções, rodovias, ferrovias, comércio, serviços de portos e aeroportos (CAMPOS, 2017). Também necessitava de profissionais para as instituições sociais e administração pública, federal, estadual e municipal.

Os interesses dos setores econômico, agrícola, industrial e comercial, dos governos e empresários forjaram um capitalismo dependente e periférico sob base primária agroexportadora e trabalho semiqualificado. Nestas condições, em que as tarefas básicas não exigiam conhecimentos elaborados, quando tinham necessidades, buscavam trabalhadores no exterior. Esta prática política levou ao surgimento de uma dualidade estrutural e orgânica na educação pública em todo o país. Uns, os abastados foram direcionados para Educação Superior, e outros, a maioria, os trabalhadores, camponeses, pobres, mulheres e subalternos foi destinada a formação primária ou ensino profissional. Esta situação de dualidade estrutural travou iniciativas de criação de um sistema nacional de educação, dificultou financiamento público adequado e explicitou as mazelas regionais nos estados e municípios. Em toda a sociedade brasileira persistia um determinismo social (SILVA, 2017) em que políticos, juízes, religiosos e donos dos meios de produção estabeleciam o lugar social e os anos de escolaridade dos trabalhadores, das mulheres, os excluídos, e assim instituíam, na legislação oficial, barreiras jurídicas que sustentavam a ordem e o progresso.

Por muitas décadas, as iniciativas educacionais permaneceram subordinadas às necessidades do modo de produção econômico, da indústria, comércio, serviços de transportes, de eletricidade, construção civil, infraestrutura e dos serviços em geral. Depois, a presença de indústrias estrangeiras, o crescimento das indústrias nacionais, o setor de comércio, bancos, rodovias, portos e exportações e o setor de serviços em geral passaram a exigir trabalhadores 
qualificados e especializados. Foi, portanto, no reino da necessidade real que a educação pública tornou-se objeto de disputa entre os interesses privatistas, religiosos e publicistas.

Outro estrangulamento veio quando a Lei n 9.424/97 (BRASIL, 1997), que criou o Fundo de Manutenção e Desenvolvimento do Ensino Fundamental e Valorização do Magistério FUNDEF excluiu o Ensino Médio regular do financiamento. Só em 2007, depois de muitas lutas, manifestações, audiências e marchas, o Fundo de Manutenção e Desenvolvimento do Ensino Fundamental e Valorização do Magistério - FUNDEB incorporou o Ensino Médio no cálculo dos recursos públicos. Nas décadas seguintes, forças conservadoras empresariais e governo federal propuseram e aprovaram o Decreto $n^{\circ} 5.154 / 04$ (BRASIL, 2004), que instituiu um tipo de a educação profissional ofertada por meio de cursos e programas: I qualificação profissional, inclusive formação inicial e continuada de trabalhadores; II - educação profissional técnica de nível médio; e III - educação profissional tecnológica de graduação e de pós-graduação.

Neste interregno, no âmbito internacional, após 2008, o modo de produção capitalista buscava outros espaços e nichos para expandir seus negócios, entre eles, a educação abria possibilidades de rendimentos. Forças políticas e econômicas, partidos políticos, setor religioso e corporações empresariais aturam com proposições externas prescritas em conferências, convenções, convênios e acordos que, depois, foram traduzidos em programas, projetos e legislação nacional como se fossem de interesses locais. Por conseguinte, empresários, partidos políticos e governos passaram, então, a divulgar, na imprensa, dados estatísticos sobre desemprego e sua associação com a insuficiência do Ensino Médio e, ao mesmo tempo, as vantagens de investidores de capitais e fundos, ávidos em explorar o ensino e a educação como negócios rentáveis.

Em todo país avançou uma onda de redução dos direitos sociais, previdenciários e trabalhistas. Em várias cidades explodiram inúmeras manifestações de rua em favor da manutenção do status quo vinculado ao projeto econômico dos grupos neoliberais e, concomitantemente, também explicitaram os confrontos e muitas formas de resistências: as jornadas de julho de 2013, 2014, 2015 e 2016, os movimentos de ocupação de escolas secundárias (BOUTIN; FLACH, 2017), dos institutos federais e universidades públicas, as manifestações dos professores no Paraná, São Paulo e Rio de Janeiro são expressões deste dissenso e do confronto aberto e muito tenso dos trabalhadores contra a redução de direitos sociais conquistados na Constituição Federal de 1988. 
Em 2014, intensificaram os interesses e forças empresarias, políticas, jurídicas e midiáticas forjaram a abertura do país para os negócios rentáveis na educação pública brasileira. Estes senhores do capital, rentistas, diante dos desequilíbrios financeiros, recompuseram os instrumentos de ganhos e sustentaram um projeto inscrito no documento A travessia social: uma ponte para o futuro, do Partido do Movimento Democrático Brasileiro, em que preceituam como ampliar os espaços para o capital e disciplinar as contestações sociais. Aponta que

Os motores possíveis para o novo crescimento, com o consequente aumento de emprego e renda são o investimento privado e as exportações... Os campos naturais de atração de investimento privado serão as concessões de infraestrutura e a criação de bens de alto benefício social por meio de arranjos institucionais público-privados, nas áreas de habitação popular, de saneamento e transporte urbano de alta qualidade (PARTIDO..., 2015, p. 8).

Na educação pública, a face visível do projeto hegemônico conservador se expressa na adoção das parcerias público-privadas, os contratos de gestão, nas fundações e associações privadas dentro das instituições públicas. Contudo, cada vez mais, as empresas privadas com fins lucrativos são tomadas como modelos a serem incorporados nas instituições universitárias, institutos e na Educação Básica pública.

Entretanto, as tensões inter forças econômicas nacionais e a recomposição de ganhos incidiram e confrontaram os rumos do projeto econômico nas eleições presidenciais de 2014. Estas forças hegemônicas insatisfeitas com a condução deste projeto conservador hegemônico, depuseram a presidente Dilma Vanna Roussef e, em seguida, deram um Golpe Parlamentar, Jurídico e Midiático em 31 de agosto de 2016, tornando Michel Temer presidente da República. Para o Ministério da Educação, nomeou o administrador de empresas José Mendonça Bezerra Filho e Maria Helena Guimarães Castro, secretária executiva e braço dos interesses empresariais privados, com a tarefa de modernizar o Ensino Médio, sob a lógica pragmática, flexível e polivalente. Nesta transição alinharam-se as forças partidárias, em vários ministérios, dispostos a executar o projeto conservador neoliberal racional, flexível e competitivo sob a lógica do capital.

Sob muitas polêmicas e com ampla veiculação de propaganda oficial na imprensa televisiva, em um franco processo de despolitização dos estudantes, o ministério da Educação passou a difundir uma concepção de Ensino Médio regular com inúmeras convergências com as proposições do Banco Mundial. Foi o retorno e a restauração conservadora (MOLL, 2017) do grupo político que usurpou o Ministério da Educação e secretarias, e logo abandonou as Diretrizes Curriculares Nacionais para o Ensino Médio, construídas pelo Conselho Nacional de 
Educação e homologadas pelo ministro da Educação Fernando Haddad, em 2011, que congregava uma concepção de integração curricular, respeito a pluralidades de conhecimentos e experiências em todo país. Este grupo conservador também se recusou a fomentar os meios para a implementação da Lei $n^{\circ}$ 13.005/2014 - Plano Nacional de Educação (BRASIL, 2014) ao minar as fontes de financiamento público. Na mesma perspectiva, reintegraram aliados e parceiros da ideologia neoliberal para compor a BNCC - Base Nacional Curricular Comum do Ensino Fundamental e do Ensino Médio. Para estas ações, governo, ministros e executivos de empresas estenderam as parcerias com os meios de comunicação e mídias com a intenção de persuadir e convencer todos de que aquela é a proposta de todos.

A propaganda oficial do governo, repetida inúmeras vezes em horário nobre da televisão, manipulou e vendeu a informação de que os adolescentes e jovens poderiam escolher os seus itinerários formativos. É falso. Primeiro porque as escolas do país não têm condições estruturais, materiais e até mesmo espaço físico para isto; segundo, há falta de professores de conteúdos disciplinares específicos do Ensino Médio; terceiro, é necessário ouvir os alunos, mas não deste jeito; quarto, trata-se, de fato, do determinismo social: isto é, para os adolescentes empobrecidos, desempregados, trabalhadores precarizados, o destino reservou trabalhos manuais e mecânicos, que quase não exigem conhecimentos elaborados. Dito de outro modo, cabe a eles vender, de forma precária, o seu trabalho aos dons dos meios de produção.

Nesta unidade de contrários e tensões, floresceram os dissensos e vieram à tona os confrontos do Movimento Estudantil Secundaristas e Universitário, com ocupações em diversas cidades de escolas secundárias, institutos federais, e de algumas faculdades e institutos dentro das universidades públicas, contra a Medida Provisória no 746/2016 (BRASIL, 2016). Parte dos estudantes reagiu e protestou. Então, a disputa pela educação pública encontra-se perpassada pelos interesses de grupos empresariais internacionais. Aqui se constata uma das convergências dessa reforma, com as proposições do Banco Mundial ao afirmar que

[...] a educação é crucial para ao crescimento econômico e para a redução da pobreza [...]. A educação, especialmente a básica, contribui para reduzir a pobreza e ao aumentar a produtividade dos pobres, reduzir a fertilidade e melhorar a saúde além de dotar as pessoas das aptidões de que necessitam para participar plenamente na economia e na sociedade (BANCO MUNDIAL, 1996, p. 23).

Ou ainda,

Desigualdades persistem e certos grupos-minorias, mulheres e os pobres - são desproporcionalmente excluídos. As taxas de evasão são altas em muitas regiões, fazendo com que só dois terços das crianças que começam a escola atinjam o quinto ano. 
Muitas crianças estão recebendo ensino de baixa qualidade, baseado em currículo antiquado e inadequado. O resultado é a obtenção de baixa pontuação em testes e a existência de diplomados desempregados e com habilidades erradas (BANCO MUNDIAL, 1999, p. vii).

Em 2017 e 2018, o Governo Federal retomou as negociações com o Banco Mundial para a viabilização de outro empréstimo, para os próximos cinco anos, conforme o excerto figura 1 a seguir:

Figura 1 - Comunicado $n^{\circ} 4$ da Comissão de Financiamentos Externos

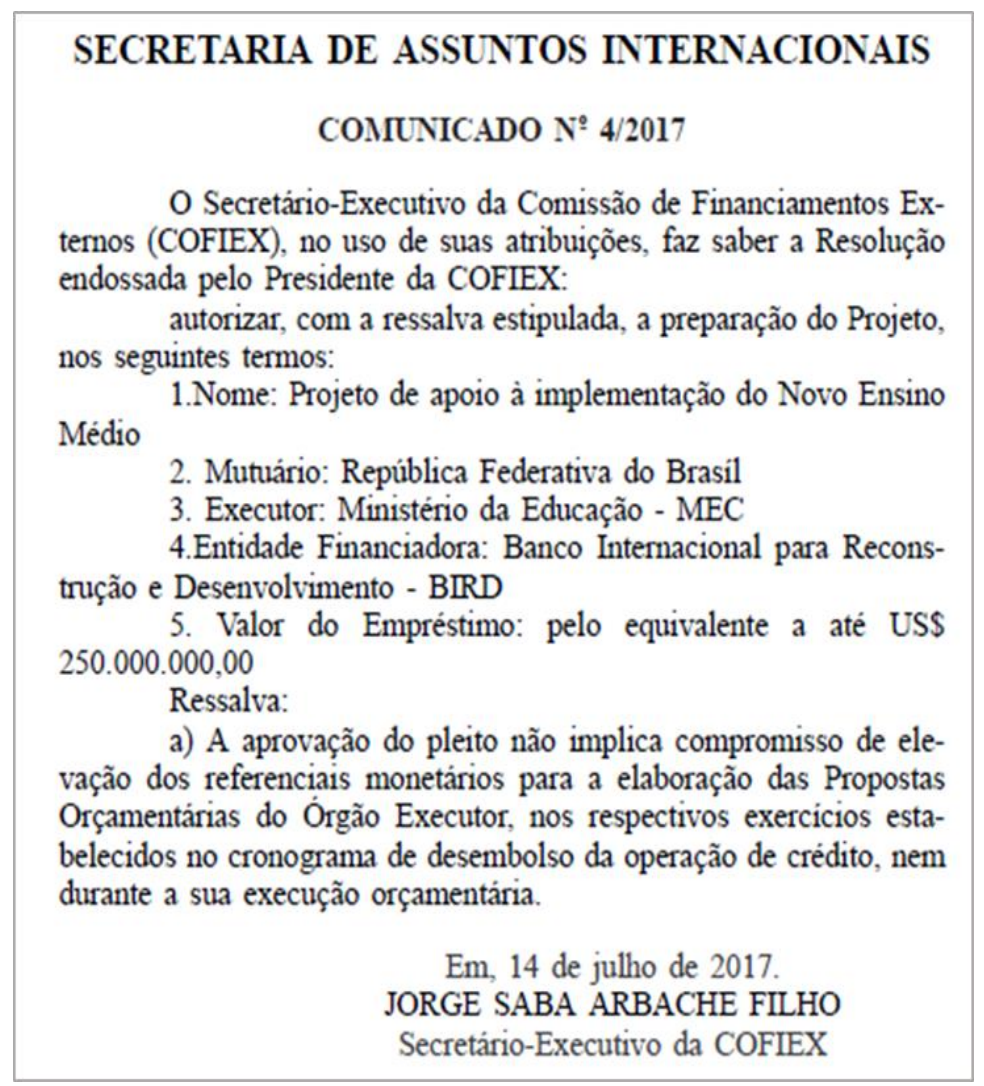

Fonte: ARBACHE FILHO, Jorge Saba. Secretaria de assuntos internacionais. Comunicado $n^{\circ}$ 4/2017. DOU, Brasília, n. 17, jul. 2017, seção 3. p. 126.

Em 2017, o Ministério da Educação divulgou as tratativas para outro empréstimo com o Banco Mundial, no valor de duzentos e cinquenta mil de dólares para implementação da reforma do Ensino Médio. Para o Componente I, o valor era de 221 milhões de dólares, e o objetivo foi apoiar a implementação do currículo e fomentar a implementação da modalidade de Ensino Médio em tempo integral. No componente II, o valor era de 29 milhões de dólares, e o objetivo foi dar assistência técnica e fortalecer a capacidade institucional do MEC, e prestar apoio às secretarias estaduais e distrital. Assim, reforçaria a competência para a execução das atividades 
no novo Ensino Médio, permitindo a contratação de serviços de consultoria especializada de alto nível.

Novamente, cabe desconfiar da necessidade deste empréstimo com o Banco Mundial, pois estudos de Romanelli, (2003); Zanardini (2012); Libâneo (2016); Souza (2017); e Leher; Vittoria; Mota (2017) indicam que tais empréstimos, com juros altos, geram mais perdas e retrocessos na conquista do direito à educação, na concepção, fins e finalidades, enfim, na Educação pública brasileira. Por outro lado, ainda apontam que o Governo Federal continua transferindo montantes significativos de juros no pagamento da dívida aos credores estrangeiros (REIS, 2016).

Ao prevalecer esta posição do governo federal, cabe indagar sobre os recursos, pois uma das condicionalidades do Banco Mundial é que, primeiro, o país desembolse os seus recursos. Depois, ser for avaliado positivo, então, o país passa a receber, de forma programada, a parte financiada pelo banco. Outra questão a ser pensada é que o Governo Federal aprovou a Emenda Constitucional 95/2016 (BRASIL, 2016) e contingenciou os recursos públicos por vinte anos. Se esse governo, representante dos interesses empresariais, atua com cortes significativos nas políticas sociais, em especial na Educação, como vai desembolsar recursos para o Ensino Médio?

Alguns estudos científicos de Souza (2017), Fonseca (2011) e Pereira (2010) demonstraram que esses empréstimos são funestos para a população do país, em razão dos altos juros e rígidas condicionalidades prescritas. Mesmo assim, são vangloriados pelos governos federal e estaduais como saída para obter os recursos financeiros. No fundo, essa repetida estratégia expressa a associação de interesses entre as agências multilaterais, bancos e grandes conglomerados de empresas transnacionais que, aqui, ampliam seus negócios, e do governo federal e das elites empresariais do setor de Educação no país.

\section{Que implicações a Lei no $13.415 / 2017$ trouxe para a Educação Básica?}

Ao ser aprovada, esta Lei trouxe implicações para viabilização, por exemplo, no artigo 13, que institui a Política de Fomento à Implementação de Escolas de Ensino Médio em Tempo Integral. Questiona-se a veracidade deste artigo, pois parte significativa dos estudantes é de trabalhadores, mulheres, mães e trabalhadoras. Pesquisas indicam que, entre as razões de abandono e desistência em concluir os estudos, estão as dificuldades de conciliar tempo dos 
estudos com o tempo do trabalho e compromissos familiares. Como, então, se fará a implementação de escolas de Ensino Médio em tempo integral?

Sobre os fins e finalidades do Ensino Médio, estes se referem aos valores e princípios a serem assumidos e vividos na formação escolar de adolescentes e jovens, segmentos excluídos da população, mas que buscam, na Educação, um alento de desenvolvimento pessoal, intelectual, artístico e cognitivo. Na verdade, o que está em disputa, novamente, são as formas de distribuição de bens culturais. Como distribuir bens culturais igualmente? Como expandir o Ensino Médio como direito, se cada vez mais os neoliberais exigem encurtar direitos? Eis a contradição! Deste modo, o dualismo estrutural educacional foi revisitado, indicando que o acesso ao Ensino Médio é definido pela condição socioeconômica do estudante ou da família, e o conhecimento a lhes ser transmitido é limitado, rudimentar e básico.

Em relação ao currículo escolar, exige-se avançar para o cerne da política econômica, a reestruturação produtiva, que sustenta um tipo de trabalhador polivalente e flexível, com destreza para se adaptar às cadeias globais de produção. Pouco importa a carga horária: "art. 24. Ampliação da carga horária mínima anual de 800 horas para 1400 horas”, pois as reais condições de funcionamento das escolas de Ensino Médio, em todo o país, estão longe da realidade dos alunos. Não se muda a formação escolar com aumento da carga horária e ênfase nas práticas. Pode-se, talvez, alterar a formação com ênfase em projetos científicos, tecnológicos, artísticos, ambientais, construção civil, engenharias, alimentação e de saúde, se articulados e vinculados com o desenvolvimento científico das universidades, faculdades, centros de pesquisas, laboratórios, outros locais de produção de conhecimento.

Observe que o art. 26 (BRASIL, 2017) diluiu os temas transversais em conteúdos esparsos, e jogou por terra todo o esforço dispensado na formação de docentes para o ensino de História, Filosofia, Educação Física, Artes e Música como constituintes da formação humana. Nesta linha, ao desprezar a formação nas Ciências Humanas e Sociais, propôs, no artigo 34 (BRASIL, 2017), o ensino da língua portuguesa, matemática e inglês como obrigatórios nos três anos do Ensino Médio, muito necessário na formação do estudante, mas, na essência, camufla o estreitamento curricular consoante com os testes e exames externos.

Sobre a questão da qualidade de ensino propalada pelo Governo Federal, executivos e diretores de multinacionais têm sua base nos padrões de qualidade vindos das práticas comerciais, industriais e mercantis. Além da polissemia que este conceito carrega, a qualidade de ensino, ensejada e proposta nos documentos do Banco Mundial (1996), World Bank Group 
(2011), UNESCO (2015) e da OCDE (2006), está associada às métricas, aos indicadores internacionais, dados estatísticos universais e comparáveis, medidas, tabelas, formulas numéricas, currículos homogeneizados e adequados para testes, exames e rankings. Nesta lógica, qualidade de ensino significa: (i) que o capital pode contar, em abundância, em uma determinada região, com trabalhadores empregáveis; (ii) uma seleção de países onde o capital financeiro pode pousar e lucrar; (iii) sinônimo de resultados alcançados na lógica empresarial; (iv) dentro dos preceitos neoliberais significa maior eficácia e eficiência no uso dos recursos públicos e maior produtividade dos sistemas de ensino; (v) uma educação de resultados mensuráveis em que os dados estatísticos são utilizados para comparação entre os países mais rentáveis para negócios promissores.

Observe que a fala do diretor do Departamento de Educação da OCDE, Andreas Schleicher, ao analisar os resultados do Pisa, preconizou que a qualidade na Educação é revelada, sobretudo, quando "estudantes alcançam seu melhor nível de desempenho em um ambiente positivo de aprendizagem, orientado para resultados" (SCHLEICHER, 2005, p. 12). Aponta, ainda, os benefícios da política de resultados:

[...] a comparação leva em consideração um modelo de sistema escolar flexível que concede alto nível de responsabilidade às escolas; e, ao mesmo tempo, garante que essas escolas se submetam a uma análise minuciosa e ao cumprimento de padrões, por meio de um sistema de avaliação externa baseado em resultados e de uma intervenção intensiva centrada nos problemas mais importantes (SCHLEICHER, 2005, p. 66).

Em uma direção contrária, Russo (2007, p. 75) afirma que a "qualidade de ensino depende sempre dos referenciais adotados para sua construção e avaliação. Não é algo absoluto, que pode ser quantificado ou classificado com alguns atributos físicos da matéria”. Qualidade é um constructo, isto é, uma categoria socialmente construída e que depende, assim, das opções axiológicas dos sujeitos com ela envolvidos. Adiciona-se ainda que qualidade social da educação aglutina os fatores socioeconômicos, culturais, concepções de mundo, de sociedade, valores, princípios, financiamento público adequado, reconhecimento social e perspectivas de pleno desenvolvimento humano, cognitivo, intelectual, artístico e ético. A categoria qualidade social resulta das relações humanas, de um juízo de valor. Sua aferição é produzida socialmente nas relações ao longo do tempo e espaços e, assim, qualidade, incorpora diferentes culturas, expectativas, valores, visões, crenças e tradições em um constante movimento de transformações.

Nestas condições reais, são profundas as implicações na formação do Ensino Médio: fragmentação e superficialidade da aprendizagem, revisitação do determinismo social, 
competências e habilidades temporárias, estreito treinamento, conteúdo pragmático e rudimentar, pois a história da Educação já demonstrou que a formação escolar não significa formação para as exigências dos setores produtivos em constantes mudanças. O Ensino Médio integra a política econômica hegemônica em curso no país, e as escolas, diretores, professores, coordenadores e estudantes são lançados no mundo da concorrência e competição, como objetos desumanizados e alienados que fazem parte das engrenagens do mercado de negócios. A lógica é explorar os trabalhadores e induzir consumidores para os produtos disponíveis no mercado.

Portanto, ao dissimular os fins, finalidades e objetivos do Ensino Médio, o Governo Federal aproxima-se das políticas externas ao uniformizar e estreitar currículo escolar; escamoteia a concorrência e competição como instrumentos para aferir a qualidade da Educação, premiação de professores e aplicação de testes e exames aos estudantes. São elementos que reforçam os dualismos na educação brasileira, ao permitir um tipo de acessibilidade segregativa e excludente dos estudantes, direcionando-os segundo suas condições sociais e econômicas e situações regionais.

\section{Implicações da Lei $n^{0}$ 13.415/2017 no trabalho e formação de professores}

Em relação aos processos de formação de professores, prevalece o alinhamento com as proposições dos organismos multilaterais, constantes no documento intitulado Professores excelentes: como melhorar a aprendizagem na América Latina e Caribe (BRUNS; LUQUE, 2015) e em Professores são importantes: atraindo, desenvolvendo e retendo os professores eficazes (OCDE, 2006), que são produções que indicam que tipo de formação se espera do docente que atua na Educação Básica.

Conhecimento sólido relacionado à disciplina; habilidades de comunicação; capacidade para se relacionar com o estudante; habilidade de auto-gestão; habilidades organizacionais; habilidades de gerenciamento de sala de aula; habilidades de resolução de problemas; repertório de métodos de ensino; habilidades de trabalho em equipe; e habilidade de pesquisa (OCDE, 2006, p. 105).

Desta proposição externa e dos cálculos e resultados internos, o governo federal insiste em avaliar os professores e, nesta linha, criou o Sistema Nacional de Certificação e Avaliação Docentes em franca expansão. No fundo, governo federal, UNESCO (2015) e OCDE (2006), juntos, estão dispostos a alterar a formação e o trabalho dos professores. Observe as seguintes prioridades no documento A travessia social: uma ponte para o futuro: 
1 - Prioridade para o ensino fundamental e médio;

2 - Foco na qualidade do aprendizado e na sala de aula;

3 - Maior presença do governo Federal no ensino básico;

4 - Dar consequência aos processos e resultados das avaliações;

5 - Foco na qualificação federal dos professores de $1^{\circ}$ e $2^{\circ}$ graus em todo país, para efeito de pagamento de um adicional à sua remuneração regular, custeado pela União;

6 - Diversificação do ensino médio, de acordo com a vocação e o interesse dos alunos. (PARTIDO..., 2015, p. 16).

No trecho selecionado, destaco os números 4 e 5, pois explicitam as convergências entre ODCE e Banco Mundial e o Governo Brasileiro, na questão da formação de professores. É neste contexto que estão inseridos os artigos 35 e 36, que dispõem sobre profissionais com notório saber reconhecido pelos respectivos sistemas de ensino para ministrar conteúdos de áreas afins à sua formação ou experiência profissional. A flexibilização da habilitação profissional dos trabalhadores em Educação, pois professores bacharéis, sem formação pedagógica e com cursos de curta duração podem exercer a docência. Flexibilizar significa contratação temporária ou por hora aula, dispensa de professores no final ano letivo, terceirização, bonificação ou premiação dos melhores, precarização da docência ao incluir de acordo com art. 61, § IV da Lei n 9.394/96 "profissionais com notório saber reconhecido pelos respectivos sistemas de ensino, para ministrar conteúdos de áreas afins à sua formação ou experiência profissional, atestados por titulação especifica ou prática de ensino em unidades educacionais da rede pública ou privada" (BRASIL, 1996). Flexibilizar significa por fim à estabilidade da carreira docente. E nesta direção, pode-se estar a caminho da dispensa de concurso público para o ingresso na carreira docente, o desinvestimento na formação de professores das Ciências Humanas, como Filosofia, História, Sociologia, Psicologia e Artes, junto com os programas de bonificação e premiação, que são medidas que desvalorizam a docência e os docentes.

Em consonância, os governos estaduais adotam programas consoantes com a política da meritocracia, pois se busca avaliar a formação do professor, exige-se assiduidade, premia e recompensa alguns, dispensa outros, mas, de forma encoberta, vive-se um profundo processo de desvalorização do trabalho docente por meio dos planos de carreira, salários insuficientes, restrição da autonomia pedagógica, oferta de conteúdos prontos em apostilas, pacotes pedagógicos e na concepção pragmática e utilitária para a formação do professor.

Quanto aos professores, permanece a lógica mercantil de transformá-lo em um trabalhador alienado, destituído de consciência de seu trabalho pela captura de sua autonomia pedagógica e intelectual, pela oferta de materiais e pacotes pedagógicos prontos para serem 
executados. A desvalorização e precarização do trabalho docente continuam presentes na carreira profissional, nos salários, na farsa de conceder bonificações e premiações, adoção de contrato de trabalho via terceirização, pois, agora, busca-se destituí-los de um corpus de conhecimentos pedagógicos, políticos e científicos, próprios da profissão, lançando-os no reino pragmático e utilitário do mundo dos negócios lucrativos e rentáveis (FREITAS, 2012; FRIGOTTO, 2017; DUARTE; DERISSO, 2017).

\section{Notas para outras reflexões}

O Banco Mundial, OCDE e Unesco, ao longo de suas trajetórias, tomaram o slogan Educação como aprendizagem ao longo de toda vida como um ideário a ser assumido e seguido por empresários, governos, ministros de Estado, chefes e executivos. Eles insistem na educação pública fundada na perspectiva da teoria do capital humano com prioridade para competências, habilidades e flexibilidade, como instrumento para o crescimento econômico, aumento da produtividade e alívio da pobreza. Na teoria do capital humano estão os pilares fundantes de uma educação de resultados, pragmática e utilitária sob a lógica da padronização, rankings, indicadores para comparação, padrões, incidindo sobre o Ensino Médio, currículo escolar, formação de professores, transformando o setor educacional em um mercado de negócios rentáveis.

Há convergência entre as formulações do Banco Mundial e a OCDE e o Governo Federal, partidos políticos e empresários, conformando uma tríplice governança na política educacional. Atuam nas reformas trabalhista, da previdência e da educação, na expansão de mercado privatização da educação pública, com medidas que alteram sua natureza pública e estatal, transformando-a em um nicho de investimentos financeiros. Mas há resistências e contestações populares!

De modo que a reforma do Ensino Médio trouxe três implicações: qualidade do ensino, pois os documentos prescrevem o significado de qualidade associado com as métricas, os indicadores internacionais, medidas, fórmulas universais, testes e padrões a serem atingidos pelos países; fins e finalidades da educação, pois anunciam os valores, princípios que a sociedade brasileira assume como seus, embora não os sejam. Os princípios carregam as concepções que assumimos na formação humana. Para quê e para quem? Eles evidenciam, na sociedade de classes, as formas de distribuição dos bens culturais, pois uns são eleitos para dirigir, e a outros, a 
maioria, resta vender sua força de trabalho. Ainda, a formação e o trabalho do professor revelaram as medidas e ações de desvalorização da docência e dos docentes. Persiste um embate de teorias, concepções filosóficas e práticas na formação inicial e continuada dos professores. Um grupo conservador neoliberal atua na execução da concepção pragmática, competitiva e utilitária: nela o professor age de forma alienada e serve ao mercado; outros grupos, heterogêneos e plurais, atuam com a concepção da práxis revolucionária, pois compreende o ser social, na sua relação com o outro e com a natureza. Compreende o trabalho, e em particular o trabalho docente, como objetivação do humano em nós, e os processos educativos proporcionam o desenvolvimento de formas superiores de visão, de consciência, e nos torna seres humanos e sociais.

Deste modo, ao enfraquecer a escola pública, diretores, professores, coordenadores e estudantes pode ser uma estratégia para expansão do setor privado, organizações sociais tidas como capazes de obter maior produtividade nos serviços públicos. Então, a institucionalidade e a prescrição legal estão mantidas, mas se restringe o princípio da gratuidade, do pluralismo de concepções filosóficas e pedagógicas, enfim, o direito ao conhecimento e o direito à educação para todos. Não se trata de eliminar o direito à educação, mas de aprisionar as escolas, os conteúdos, os saberes, os livros didáticos, e submeter os estudantes aos testes, exames e indicadores que fotografam a realidade, mas não captam a complexidade do ambiente escolar, com vista à manutenção do determinismo social e econômico, ainda que sob muitas formas de resistências e contestações populares. Sigamos na luta! Cada vez mais árdua!

\section{Referências}

BANCO MUNDIAL. Education sector strategy. Washington, D.C.: Banco Mundial, 1999. BANCO MUNDIAL. Prioridades y estrategias para la educación. Washington, D. C.: Banco Mundial, 1996.

BOUTIN, Aldimara C. D. B.; FLACH, Simone de F. O movimento de ocupação de escolas públicas e suas contribuições para a emancipação humana. Inter-ação, Goiânia, v. 42, n. 2, p. 429-446, maio/ago. 2017.

BRASIL. Ministério da Educação. Medida Provisória No 746, de 22 de setembro de 2016. Exposição de motivos. Brasília: MEC, 2016. Disponível em: https://www2.camara.leg.br/legin/fed/medpro/2016/medidaprovisoria-746-22-setembro-2016783654-exposicaodemotivos-151127-pe.html. Acesso em: 10 fev. 2018

BRASIL. Lei no 13.415/2017. Institui a Política de Fomento à implementação das Escolas de Ensino Médio em tempo integral. Brasília: Senado Federal, 2017. Disponível em: http://www.planalto.gov.br/ccivil_03/_ato2015-2018/2017/lei/113415.htm. Acesso 10 fev. 2018. 
BRASIL. Decreto $\mathbf{n}^{\mathbf{0}} \mathbf{. 5 1 5 4 / 2 0 0 4}$. Regulamenta o $\S 2^{\circ}-$ do art. 36 e os arts. 39 a 41 da Lei no 9.394, de 20 de dezembro de 1996, que estabelece as diretrizes e bases da educação nacional e dá outras providências. Brasília: Câmara dos Deputados, 2004. Disponível em: https://www2.camara.leg.br/legin/fed/decret/2004/decreto-5154-23-julho-2004-533121publicacaooriginal-16200-pe.html. Acesso em: 10 fev. 2018.

BRASIL. Lei n⿳ 9.424/1997. Dispõe sobre o Fundo de Manutenção e Desenvolvimento do Ensino Fundamental e de Valorização do Magistério, na forma prevista no art. $60, \S 7^{\circ}$, do Ato das Disposições Constitucionais Transitórias, e dá outras providências. Brasília: Câmara dos Deputados, 1997. Disponível em: https://www2.camara.leg.br/legin/fed/lei/1996/lei-9424-24dezembro-1996-365371-publicacaooriginal-1-pl.html. Acesso em: 10 fev. 2018.

BRASIL. Lei no 9.394/1996. Dispõe sobre as Diretrizes e Bases da Educação Nacional. Brasília: Senado Federal, 1996. http://www.planalto.gov.br/ccivil_03/leis/19394.htm. Acesso em: 10 fev. 2018

BRASIL. Emenda Constitucional 59/2009. Prevê a obrigatoriedade do ensino de quatro a dezessete anos e ampliar a abrangência dos programas suplementares para todas as etapas da educação básica. Brasília: Senado Federal, 2009. Disponível em:

http://www.planalto.gov.br/ccivil_03/constituicao/emendas/emc/emc59.htm. Acesso em: 10 fev. 2018.

BRASIL. Lei ${ }^{\circ}$ 13.005/2014. Plano Nacional de Educação 2014-2024. Brasília: MEC, 2014. Disponível em: http://pne.mec.gov.br/18-planos-subnacionais-de-educacao/543-plano-nacionalde-educacao-lei-n-13-005-2014. Acesso em: 10 fev. 2018.

BRASIL. Emenda Constitucional n⿳ 95/2016. Altera o ato das disposições constitucionais transitórias para instituir o novo regime fiscal e dá outras providências. Brasília: Senado Federal, 2016. Disponível em:

http://www.planalto.gov.br/ccivil_03/constituicao/emendas/emc/emc95.htm. Acesso em: 10 fev. 2018.

BRASIL. Constituição da República Federativa do Brasil. Brasília: Senado Federal, 1988.

BRASIL. MEC. INEP. Índice de Desenvolvimento da Educação Básica (IDEB). Brasília: INEP, 2015.

BRUNS, Barbara; LUQUE, Javier. Professores excelentes: como melhorar a aprendizagem dos estudantes na América Latina e no Caribe. Washington, D. C.: Grupo Banco Mundial, 2015.

CAMPOS, Pedro Henrique P. Estranhas catedrais: as empreiteiras brasileiras e a ditadura militar,1964-1988. Rio de Janeiro: FAPERJ / EDUFF, 2017.

DUARTE, Rita de Cássia; DERISSO, José Luís. A reforma neoliberal do ensino médio e a gradual descaracterização da escola. Germinal: Marxismo e Educação em Debate, Salvador, v. 9, n. 2, p. 132-141, ago. 2017.

FONSECA, Marília. Banco Mundial e educação: reflexões sobre o caso brasileiro. In: GENTILI, Pablo. Pedagogia da exclusão. 18. ed. Petrópolis: Vozes, 2011.

FREITAS, Luiz Carlos. Os reformadores empresariais da educação: da desmoralização do magistério à destruição do sistema público de educação. Educação e Sociedade, Campinas, v. 33, n. 119, p. 379-404, abr./jun. 2012. 
FRIGOTTO, Gaudêncio. A gênese das teses da Escola sem Partido: esfinge e ovo da serpente que ameaçam a sociedade e a educação. 2017 (Mimeo).

LEHER, Roberto; VITTORIA, Paolo; MOTTA, Vânia. Educação e mercantilização em meio à tormenta político-econômica do Brasil. Germinal, Marxismo e Educação em Debate, Salvador, v. 9, n. 1, p. 14-24, abr. 2017.

LIBÂNEO, José Carlos. Políticas educacionais: desfiguramento da escola e do conhecimento escolar. Cadernos de Pesquisa, Goiânia, v. 46, n. 159, p. 38-62, jan./mar. 2016.

MOLL, Jaqueline. Reformar para retardar: a lógica da mudança no Ensino Médio. Revista Retratos da Escola, Brasília, v. 11, n. 20, p. 61-74, jan./jun. 2017.

OCDE. Professores são importantes. Atraindo, desenvolvendo e retendo professores eficazes. São Paulo: Moderna / OCDE, 2006.

PEREIRA, João Márcio Mendes. O Banco Mundial como ator político, intelectual e financeiro, 1944-2008. Rio de Janeiro: Civilização Brasileira, 2010.

PARTIDO do Movimento Democrático Brasileiro. A travessia social: uma ponte para o futuro. Brasília: Fundação Ulisses Guimarães, 2015. Disponível em:

https://www.fundacaoulysses.org.br/blog/acervo/. Acesso em: 10 fev. 2018.

REIS, Luiz Fernando. Dívida pública, política econômica e financiamento das universidades federais nos governos Lula e Dilma 2003-2014. Universidade e Sociedade, Brasília, v. 26, n. 57 , p. 16-35, jan. 2016.

ROMANELLI, Otaíza. História da educação no Brasil. Petrópolis: Vozes, 2003.

RUSSO, Miguel. H. Contribuições da administração escolar para a melhoria da qualidade do ensino. In: BAUER, Carlos et al. Políticas educacionais \& discursos pedagógicos. Brasília, Líber livro, 2007. p. 69-97.

SCHLEICHER, Andreas. A melhoria da qualidade e da equidade na educação: desafios e respostas políticas. São Paulo: Moderna, 2005.

SILVA, Marcelo Lira. Coup D’ État e exclusivismo político-educacional: uma análise da medida provisória 746/2016. Germinal: Marxismo e Educação em debate, Salvador, v. 9, n. 3, p. 182 210, dez, 2017.

SOUZA, Neila Nunes. Política e gestão da educação básica pública: o programa estrada do conhecimento no Tocantins. 2017. Tese (Doutorado em Educação) - Programa de Pós-Graduação em Educação, Universidade de Brasília, Brasília, 2017.

UNESCO. Educação 2030: Declaração de Incheon e Marco de Ação; rumo a uma educação de qualidade inclusiva e equitativa e à educação ao longo da vida para todos. Coreia do Sul:

UNESCO, 2015. Disponível em: http://www.unesco.org/new/pt/brasilia/about-this-office/singleview/news/education_2030_incheon_declaration_and_and_framework_for_ac/. Acesso em: 10 fev. 2018.

VIEIRA, Evaldo. Democracia e política social. Campinas: Cortez, 1992.

WORLD BANK GROUP. Learning for All: Investing in People's Knowledge and Skills to Promote Development: World Bank Group Education Strategy 2020. Washington, D.C.: World Bank. 2011. Disponível em: http://pubdocs.worldbank.org/en/418511491235420712/EducationStrategy-4-12-2011.pdf. Acesso em: 10 jan. 2018. 
SILVA, Maria Abádia. A contrarreforma do Ensino Médio - Lei 13.415/2017: educação de resultados?

ZANARDINI, J.B. Educação eficiente como estratégia para alívio da pobreza. Germinal: Marxismo e Educação em Debate, Salvador, v. 4, n. 2, p. 100-109, dez. 2012. 